\title{
High Blood Pressure Knowledge Among Primary Care Patients with Known Hypertension: A North Carolina Family Medicine Research Network (NC-FM-RN) Study
}

\author{
Anthony J. Viera, MD, MPH, Lauren W. Cohen, MA, C. Madeline Mitchell, MURP, and \\ Philip D. Sloane, MD, MPH
}

Background: We sought to assess primary care patients' current knowledge about various aspects of high blood pressure (BP).

Methods: We mailed a questionnaire to 700 hypertensive patients enrolled in a practice-based research network cohort from 24 practices in North Carolina. We determined percentages of respondents (total and by subgroups) incorrectly answering each of 6 questions pertaining to various aspects of high BP. We then examined bivariate and multivariate associations with answering 2 or more items incorrectly ("lower hypertension knowledge").

Results: We received 530 completed surveys (76\% response rate). Twenty-six percent $(95 \%$ CI, $22-$ 30) of respondents did not know that most of the time people with high BP do not feel it. Twenty-two percent (95\% CI, 18-26) either were not sure whether anything could be done to prevent high BP or believe that there is nothing that can be done. Nineteen percent (95\% CI, 16-22) either believe taking medications will cure high BP or are not sure whether it will.

Twenty-two percent (95\% CI, 19-26) of respondents had overall lower hypertension knowledge. Independent associations with lower hypertension knowledge were African-American race (odds ratio, 1.77; 95\% CI, 1.10-2.86), having less than high school education (odds ratio, 2.43; 95\% CI, 1.34-4.41), and history of stroke/mini-stroke (odds ratio, 1.94; 95\% CI, 1.00-3.75).

Conclusions: Patients may need to be taught the difference between curing hypertension and treating it with medications. Efforts to educate the public that lifestyle modifications can prevent hypertension and that it usually causes no symptoms need to continue. It seems especially important to develop messages that reach African-Americans and people with less education. (J Am Board Fam Med 2008;21: 300-308.)

Over the last 3 decades, considerable progress has been made in the detection, treatment, and control of high blood pressure (BP) in the United States. During 1976 to $1980,50 \%$ of adults with hypertension were unaware of it, $70 \%$ were not being treated, and only $10 \%$ had their BP under con-

This article was externally peer reviewed.

Submitted 13 November 2007; revised 9 February 2008; accepted 15 February 2008.

From the Department of Family Medicine (AJV, PDS) and the Cecil G. Sheps Center for Health Services Research (LWC, CMM, PDS), The University of North Carolina at Chapel Hill.

Funding: Funded in part by the Small Grants Program, Department of Family Medicine, The University of North Carolina at Chapel Hill.

Conflict of interest: none declared.

Corresponding Author: Anthony J. Viera, MD, MPH, Department of Family Medicine, University of North Carolina at Chapel Hill, CB 7595, Manning Drive, Chapel Hill, NC 27599-7595 (E-mail: anthony_viera@med.unc.edu). trol. ${ }^{1,2}$ Around this same time, less than $25 \%$ of Americans knew that hypertension can lead to stroke and heart disease. ${ }^{2}$ Recognizing the need to increase the public's knowledge about hypertension, the National Heart, Lung, and Blood Institute coordinated the establishment in 1972 of the National High Blood Pressure Education Program (NHBPEP). The goal of the NHBPEP is to reduce death and disability related to high $\mathrm{BP}$ through programs of professional, patient, and public education. ${ }^{2}$ Today, more than $75 \%$ of Americans are aware that hypertension can lead to strokes and heart disease. ${ }^{2}$ This increased knowledge about hypertension parallels an increase in detection, treatment, and control of high BP. In 2003 to 2004, approximately $75 \%$ of adults with hypertension were aware of it, $65 \%$ were being treated, and $37 \%$ had their BP controlled (57\% among those treated). ${ }^{3}$ 
Despite this progress, hypertension remains an important public health problem, affecting at least 65 million American adults. ${ }^{3,4}$ Although the percentage of adults unaware of their hypertension has decreased by $25 \%$ since 1980 , and the percentage whose $\mathrm{BP}$ is under control has increased by $27 \%$; more than 16 million American adults currently do not know they have hypertension, and nearly 41 million still do not have their BP under control. Among several potential reasons for lack of recognition and control of hypertension ${ }^{5}$ is people's ongoing lack of knowledge about various aspects of high BP. For example, the lack of knowledge of appropriate target BP has been shown to be associated with poor BP control. ${ }^{6}$

Identification of gaps in people's knowledge about hypertension can aid in the development of messages to enhance that knowledge. The identification of groups more likely to have lower hypertension knowledge can inform the targeting of educational messages. One of the recent studies of hypertension knowledge was a national telephone survey that focused on older Americans ( $\geq 50$ years of age); this study found no overall difference in hypertension knowledge when comparing whites, Hispanics, and African-Americans. ${ }^{7,8}$ However, knowledge may be different among people younger than 50 years of age. Another of the more recent studies of hypertension knowledge was a survey of hypertension patients. That study's primary focus was on patients' understanding about the importance of systolic BP, which turned out to be rather meager. However, knowledge of certain other aspects of hypertension was good: $90 \%$ of hypertensive patients knew that lowering BP would improve health, and $82 \%$ knew the meaning of "hypertension." ${ }^{9}$ Except for a trend toward lower knowledge among those with less education, this study also did not find significant differences among subgroups. Although this study was of primary care patients, it took place in the Midwestern US. ${ }^{9}$ It is likely that there are regional variations in people's knowledge of hypertension such that an assessment of knowledge in one region may be quite different from an assessment of knowledge in another region.

We were particularly interested in assessing current basic knowledge about high blood pressure among people in North Carolina to better inform the development of community-based educational efforts in the state. The purposes of this study were, therefore, to assess basic hypertension knowledge among primary care patients in North Carolina with known high BP, to determine whether knowledge of various aspects about hypertension varies across subgroups, and to identify factors associated with lower hypertension knowledge in this population.

\section{Methods \\ Overall Design}

We conducted a cross-sectional survey of adults from a cohort recruited in office waiting rooms of 24 practices in the North Carolina Family Medicine Research Network (NC-FM-RN). The practices in this sample were selected to represent the geographic regions and ethnic diversity of the state. A complete description of the scope and design of the NC-FM-RN and its cohort is presented elsewhere. $^{10}$

At enrollment, subjects completed a 4-page questionnaire containing standardized questions on chronic conditions, health habits, and demographic items. Subjects were asked if they were willing to be contacted for future studies, and $81.9 \%$ granted permission. ${ }^{10}$ The current study surveyed a sample of these individuals. This study was approved by the Institutional Review Board of the University of North Carolina at Chapel Hill.

\section{Questionnaire}

The original primary intent of the questionnaire was to explore the prevalence of home BP monitoring and factors associated with its use. Once the initial questionnaire was developed, we pilot tested it in a focus group of nurses, nursing assistants, and medical assistants. The questions were assessed for clarity, and we modified some items based on comments during the focus group. The final questionnaire has a Flesch-Kincaid reading grade level of 5.6. ${ }^{11}$

We had hypothesized that people with greater hypertension knowledge would be more likely to use home BP monitoring. We therefore included 6 items drawn from a 12-item questionnaire designed by the National Institutes of Health for assessment of high BP knowledge among nonmedical individuals. ${ }^{12} \mathrm{We}$ did not include all 12 because we sought to minimize response burden. We chose an item specific to the importance of high BP ("High blood pressure is not life threatening"), one specific to prevention ("There is nothing you can do to pre- 


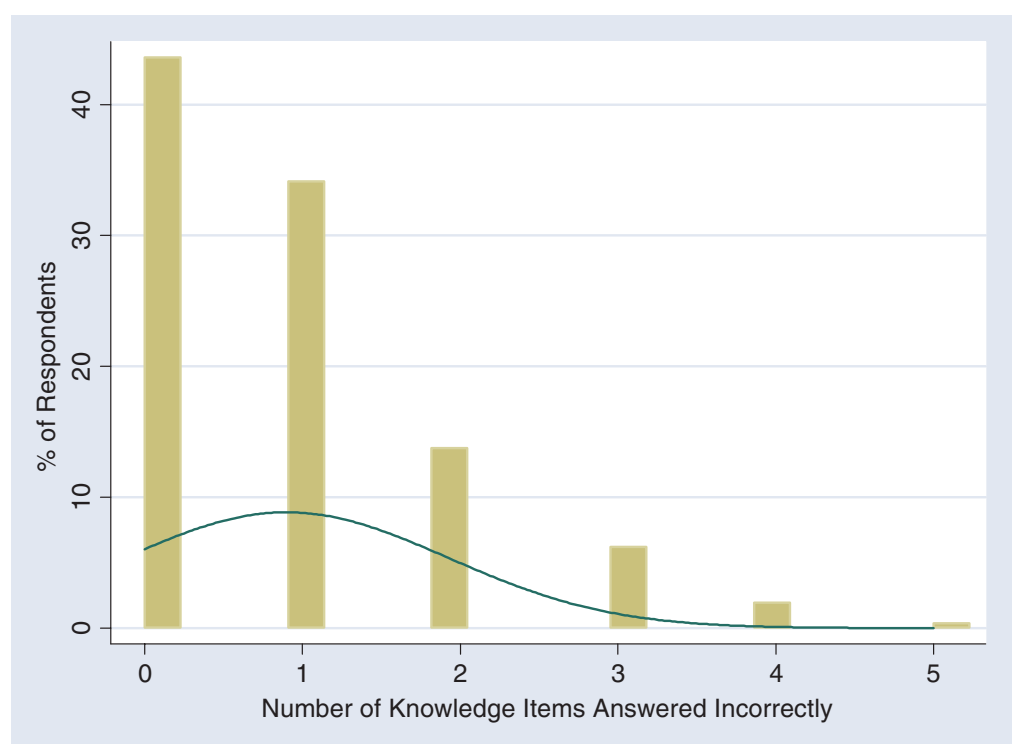

Figure 1. Number of knowledge items answered incorrectly $(n=516)$.

vent high blood pressure"), one related to screening ("Most of the time people with high blood pressure don't feel it"), one pertaining to treatment ("Taking medications will cure high blood pressure"), one relating to control ("Blood pressure is high when recorded as over 140 over $90 \mathrm{~mm} \mathrm{Hg}$ or higher"), and one about lifestyle ("Americans eat more salt and sodium than they need"). This current paper is an in-depth analysis of responses to those items.

\section{Sample}

During the year 2004 to 2005 NC-FM-RN cohort $(\mathrm{n}=2720), 1088$ patients indicated on their enrollment questionnaire that they had high BP. From these potential subjects we drew a computer-generated random sample stratified by race (446 whites and 254 African-Americans). We anticipated a $60 \%$ response rate.

\section{Survey Administration and Data Management}

The questionnaire was initially sent via US mail to 700 potential respondents. A $\$ 1.00$ bill was paperclipped to the questionnaire as a token of appreciation. Also included was a preaddressed, businessreply return envelope. A second questionnaire was mailed to nonrespondents 3 weeks later. Six weeks after the second mailing, a research assistant attempted to contact remaining nonrespondents by telephone. On receipt of completed questionnaires, data were double-entered into a Microsoft Access database. Before any analyses, the data were compared for accuracy, checked for logical errors, cleaned, and compiled.

\section{Variables}

Incorrect answers to the $6 \mathrm{BP}$ knowledge items comprised our outcome (dependent) variables. Responses of "not sure" were considered incorrect. We created a variable representing the total number of items answered incorrectly. Based on the distribution of these responses (Figure 1, described later under results), we designated a subgroup of respondents as having lower hypertension knowledge.

From the variables about respondents obtained at baseline, we included several characteristics that have been shown ${ }^{12,13}$ or were hypothesized to be associated with lower hypertension knowledge. We divided age, self-reported health status, and education level each into 3 categories. Race was divided into 2 categories. Body mass index, based on selfreported height and weight, was divided into 3 categories. Smoking status and cardiovascular conditions (heart disease, diabetes, stroke/mini-stroke) were all dichotomous based on self-report.

\section{Analysis}

After performing a series of exploratory analyses to insure the integrity of the data, we determined percentages of respondents and nonrespondents within categories of the independent variables (age, 
sex, race, education, body mass index, self-reported health status, smoking status, cardiovascular conditions). These are reported as means with standard deviations or percentages with $95 \%$ confidence intervals. We examined differences between respondents and nonrespondents using $\chi^{2}$ for percentages and the $t$ test for mean age. We determined the percentage of respondents answering none of the items incorrectly, one item incorrectly, and 2 or more items incorrectly ("lower hypertension knowledge").

Next, we determined percentages of respondents incorrectly answering each item among all respondents as well as within categories of each the independent variables. We examined bivariate associations of the independent variables with lower hypertension knowledge, testing for significance using Pearson $\chi^{2}$. Characteristics with $P<.10$ were placed into a multivariate logistic regression model to determine their independent associations with lower hypertension knowledge. We included an interaction term between race and education and tested for significance using the likelihood ratio test.

Refusals to answer questions and missing values were handled by exclusion from analysis. We considered $P \leq .05$ and $95 \%$ confidence intervals not crossing the null value to be statistically significant. All analyses were performed using Stata 8.1 statistical software (StataCorp, College Station, TX).

\section{Results}

Of 700 questionnaires mailed, there were 25 undeliverables and 11 ineligibles ( 9 deceased; 1 incarcerated; 1 did not have hypertension). After the first mailing, 433 questionnaires were returned completed. An additional 31 questionnaires were returned after the second mailing. During the period of telephone follow-up, an additional 66 questionnaires were completed. This yielded an unadjusted response rate of $76 \%$ (530 of 700), and an adjusted response rate of $80 \%$ (530 of 664).

Respondents had a mean age of $59.6 \pm 13.7$ years. The majority were women $(68.5 \%)$, white $(67.5 \%)$, overweight or obese $(86.1 \%)$, did not smoke $(79.2 \%)$, and had at least a high school education (74.4\%) (Table 1). Over one-fourth $(26.0 \%)$ reported having heart disease; one-third had diabetes, and $10.3 \%$ reported a history of a stroke/mini-stroke. Nonrespondents were more likely to be younger, African-American, men, and smokers.

Knowledge of hypertension as assessed by the selected questions was relatively high. The median number of knowledge questions answered incorrectly was one (mean, 0.90; standard SD, 1.02). Approximately $44 \%$ of respondents answered none of the items incorrectly; $34 \%$ answered one incorrectly, and $22.3 \%$ of respondents answered 2 or more items incorrectly (Table 1).

The vast majority of respondents knew that high $\mathrm{BP}$ can be life threatening and that Americans eat more salt and sodium than they need. Only $6.7 \%$ and $2.8 \%$, respectively, answered these items incorrectly (Table 2). Older people were more likely to respond incorrectly to these items. African-Americans were more likely than whites to respond incorrectly to the sodium question $(5.3 \%$ vs $1.7 \%$; $P=.02)$.

The item most often answered incorrectly was related to whether high BP usually causes symptoms. Over one-fourth (26.2\%) of respondents marked False/Not sure for the item, "Most of the time, people with high blood pressure don't feel it." Younger people, those with less education, those with poorer self-reported health, and current smokers were more likely to answer this item incorrectly (Table 2).

Approximately $22 \%$ of respondents marked True/Not sure for the item, "There is nothing you can do to prevent high blood pressure." Older people, African-Americans, those with less education, those in poorer health, and those with a history of stroke/mini-stroke were more likely to answer in this manner. Similarly, 19\% of respondents marked True/Not sure for the item, "Taking medications will cure high blood pressure." With the exception of self-reported health, factors associated with this incorrect response were similar (Table 2).

There were no differences in percentages of respondents answering any question incorrectly by sex, known heart disease, or known diabetes. Approximately $14 \%$ of respondents did not know (or were not sure) that a BP is high when recorded as over 140/90 mm Hg. This knowledge did not vary by any of the characteristics studied (Table 2).

The distribution of the sum of total knowledge items answered incorrectly (Figure 1) was skewed such that most respondents answered one or none of the items incorrectly. The minority who answered 2 or more items incorrectly was considered 


\begin{tabular}{|c|c|c|c|}
\hline & $\begin{array}{l}\text { Respondents } \\
(\% \text { [95\% CI] })\end{array}$ & $\begin{array}{l}\text { Non-respondents } \\
(\%[95 \% \text { CI }])\end{array}$ & $P$ \\
\hline Age, years (mean $[\%]$ ) & $59.6(13.7)$ & $54.2(15.8)$ & $<.001$ \\
\hline \multicolumn{4}{|l|}{ Age category (years) } \\
\hline$<45$ & $14.2(11.2-17.2)$ & $27.7(20.9-34.4)$ & \\
\hline $45-65$ & $50.4(46.1-54.6)$ & $47.1(39.5-54.6)$ & \multirow[t]{2}{*}{$<.001$} \\
\hline$>65$ & $35.5(31.4-39.6)$ & $25.3(18.7-31.9)$ & \\
\hline Male & $31.5(27.5-35.5)$ & $44.4(36.8-51.9)$ & .002 \\
\hline \multicolumn{4}{|l|}{ Race } \\
\hline African-American & $32.5(28.5-36.5)$ & $48.2(40.6-55.8)$ & \multirow[t]{2}{*}{$<.001$} \\
\hline White & $67.5(63.5-71.5)$ & $51.8(44.2-59.4)$ & \\
\hline \multicolumn{4}{|l|}{ Education } \\
\hline$<$ High school & $25.6(21.9-29.4)$ & $29.9(22.9-37.0)$ & \multirow{3}{*}{.49} \\
\hline High school graduate & $32.5(28.5-36.5)$ & $32.3(25.2-39.5)$ & \\
\hline Some college or more & $41.9(37.6-46.1)$ & $37.7(30.3-45.2)$ & \\
\hline \multicolumn{4}{|l|}{ Body mass index } \\
\hline$<25 \mathrm{~kg} / \mathrm{m}^{2}$ & $14.0(11.0-16.9)$ & $18.2(12.4-24.1)$ & \multirow{3}{*}{.23} \\
\hline $25-30 \mathrm{~kg} / \mathrm{m}^{2}$ & $30.8(26.8-34.7)$ & $25.3(18.7-31.9)$ & \\
\hline$>30 \mathrm{~kg} / \mathrm{m}^{2}$ & $55.3(51.0-59.5)$ & $56.5(48.9-64.0)$ & \\
\hline \multicolumn{4}{|l|}{ Self-reported health } \\
\hline Excellent or very good & $21.2(17.7-24.7)$ & $15.9(10.3-21.4)$ & \multirow{3}{*}{.12} \\
\hline Good & $39.5(35.3-43.7)$ & $36.5(29.2-3.8)$ & \\
\hline Fair or poor & $39.3(35.1-43.5)$ & $47.6(40.1-55.2)$ & \\
\hline Current smoker & $20.8(17.3-24.3)$ & $30.2(23.2-37.2)$ & .01 \\
\hline \multicolumn{4}{|l|}{ Other cardiovascular conditions } \\
\hline Known heart disease & $26.0(22.1-29.9)$ & $29.9(22.4-37.4)$ & .35 \\
\hline Known diabetes & $32.6(28.4-36.7)$ & $38.0(30.1-45.9)$ & .22 \\
\hline History of stroke or mini- stroke & $10.3(7.6-13.1)$ & $14.1(8.4-19.7)$ & .20 \\
\hline \multicolumn{4}{|l|}{ Hypertension knowledge } \\
\hline 2 or more items incorrect & $22.3(18.7-25.9)$ & & \\
\hline 1 item incorrect & $34.1(30.0-38.2)$ & & \\
\hline No items incorrect & $43.6(39.3-47.9)$ & & \\
\hline
\end{tabular}

to have lower hypertension knowledge. Among these $22.3 \%$ of respondents categorized as having lower hypertension knowledge, 4 factors were associated in bivariate analysis: older age, AfricanAmerican race, less education, and history of stroke/mini-stroke (Table 3). Nearly 29\% of respondents older than 65 years had lower hypertension knowledge, compared with $18 \%$ of those ages 45 to 65 and $22 \%$ of those younger than 45 ( $P=$ $.03)$. Slightly more than $29 \%$ of African-Americans had lower hypertension knowledge, compared with $19 \%$ of whites $(P=.009)$. A third of respondents with less than a high school education had lower hypertension knowledge, compared with $24 \%$ of high school graduates and $14.6 \%$ of those with some college $(P<.001)$. Almost twice as many respondents with a history of stroke/mini-stroke had lower hypertension knowledge $(39.6 \%$ vs
$20.8 \% ; P=.003)$. Although not statistically significant, a higher percentage of those in fair or poor self-reported health also had lower hypertension knowledge.

After adjustment, only African-American race, having less than high school education, and history of stroke/mini-stroke were associated with lower hypertension knowledge (Table 4). Compared with whites, African-Americans had 1.77 times the odds of having lower hypertension knowledge (95\% CI, 1.10-2.86). Those with less than a high school education had 2.43 times the odds of having lower hypertension knowledge compared with those with some college (95\% CI, 1.34-4.41). Finally, respondents with a history of stroke/mini-stroke had 1.94 times the odds of having lower hypertension knowledge (95\% CI, 1.00-3.75). The interaction between race and education was not significant $(P=.53)$. 
Table 2. Percent of Respondents Incorrectly Answering Each Knowledge Question (n = 470-527)

\begin{tabular}{|c|c|c|c|c|c|c|c|c|c|c|c|c|}
\hline & $\begin{array}{l}\text { There is } \\
\text { nothing you } \\
\text { can do to } \\
\text { prevent HBP }\end{array}$ & $P$ & $\begin{array}{l}\text { Most of the } \\
\text { time, people } \\
\text { with HBP } \\
\text { don't feel it }\end{array}$ & $P \mathrm{t}$ & $\begin{array}{l}\text { HBP is } \\
\text { not life- } \\
\text { threatening }\end{array}$ & $P$ & $\begin{array}{l}\text { Taking } \\
\text { medications } \\
\text { will cure } \\
\text { HBP }\end{array}$ & $P$ & $\begin{array}{c}\text { BP is high } \\
\text { when recorded } \\
\text { as over } \\
140 / 90\end{array}$ & $P$ & $\begin{array}{l}\text { Americans } \\
\text { eat more salt } \\
\text { d sodium thar } \\
\text { they need }\end{array}$ & $P$ \\
\hline All ages & 22.1 & & 26.2 & & 6.7 & & 19.0 & & 13.7 & & 2.8 & \\
\hline \multicolumn{13}{|l|}{ Age category (years) } \\
\hline$<45$ & 13.5 & .005 & 39.2 & .002 & 0 & $<.001$ & 12.2 & .008 & 14.9 & .71 & 2.7 & .028 \\
\hline $45-65$ & 19.2 & & 27.8 & & 4.5 & & 16.1 & & 12.5 & & 1.1 & \\
\hline$>65$ & 29.6 & & 18.8 & & 12.4 & & 26.1 & & 15.0 & & 5.4 & \\
\hline \multicolumn{13}{|l|}{ Sex } \\
\hline Male & 19.2 & .28 & 22.3 & .16 & 4.8 & .24 & 18.0 & .67 & 12.0 & .42 & 3.1 & .67 \\
\hline Female & 23.4 & & 28.1 & & 7.5 & & 19.5 & & 14.6 & & 2.4 & \\
\hline \multicolumn{13}{|l|}{ Race } \\
\hline African-American & 31.8 & $<.001$ & 28.2 & .47 & 8.9 & .16 & 14.7 & .022 & 15.9 & .32 & 5.3 & .02 \\
\hline White & 17.4 & & 25.3 & & 5.6 & & 16.3 & & 12.7 & & 1.7 & \\
\hline \multicolumn{13}{|l|}{ Education } \\
\hline$<\mathrm{HS}$ & 33.3 & .002 & 29.5 & .025 & 12.9 & .002 & 23.3 & .011 & 19.1 & .13 & 5.3 & .16 \\
\hline HS graduate & 20.6 & & 31.8 & & 4.1 & & 23.7 & & 13.1 & & 2.3 & \\
\hline Some college or more & 16.7 & & 20.3 & & 4.2 & & 13.0 & & 11.5 & & 1.8 & \\
\hline \multicolumn{13}{|l|}{ Body mass index } \\
\hline$<25 \mathrm{~kg} / \mathrm{m}^{2}$ & 26.0 & .44 & 31.5 & .54 & 13.9 & .022 & 17.8 & .85 & 11.0 & .56 & 4.1 & .77 \\
\hline $25-30 \mathrm{~kg} / \mathrm{m}^{2}$ & 19.0 & & 25.3 & & 6.8 & & 18.0 & & 12.5 & & 2.5 & \\
\hline$>30 \mathrm{~kg} / \mathrm{m}^{2}$ & 22.8 & & 25.4 & & 4.8 & & 19.8 & & 15.1 & & 2.7 & \\
\hline \multicolumn{13}{|l|}{ Self-reported health } \\
\hline Excellent or very good & 15.2 & .06 & 17.0 & .001 & 4.5 & .42 & 17.1 & .48 & 14.3 & .67 & 2.7 & .83 \\
\hline Good & 21.4 & & 22.9 & & 8.2 & & 17.6 & & 12.1 & & 3.4 & \\
\hline Fair or poor & 26.6 & & 34.6 & & 6.3 & & 21.6 & & 15.1 & & 2.4 & \\
\hline \multicolumn{13}{|l|}{ Current smoker } \\
\hline Yes & 17.6 & .22 & 36.1 & .008 & 4.6 & .38 & 17.4 & .66 & 15.6 & .53 & 1.8 & .46 \\
\hline No & 23.0 & & 23.5 & & 7.0 & & 19.3 & & 13.3 & & 3.1 & \\
\hline \multicolumn{13}{|l|}{ Known heart disease } \\
\hline Yes & 23.8 & .55 & 26.2 & .96 & 8.0 & .34 & 21.4 & .39 & 14.3 & .81 & 2.4 & .69 \\
\hline No & 21.2 & & 26.0 & & 5.6 & & 17.9 & & 13.4 & & 3.1 & \\
\hline \multicolumn{13}{|l|}{ Known diabetes } \\
\hline Yes & 25.2 & .25 & 26.2 & .96 & 8.1 & .32 & 20.7 & .45 & 14.5 & .80 & 4.4 & .24 \\
\hline No & 20.5 & & 26.1 & & 5.8 & & 17.9 & & 13.6 & & 2.4 & \\
\hline \multicolumn{13}{|c|}{ History of stroke/mini-stroke } \\
\hline Yes & 36.7 & .013 & 30.6 & .50 & 10.2 & .25 & 35.4 & .004 & 16.3 & .59 & 4.1 & .63 \\
\hline No & 21.1 & & 26.1 & & 5.9 & & 18.0 & & 13.5 & & 2.8 & \\
\hline
\end{tabular}

HBP, high blood pressure; BP, blood pressure; HS, high school.

\section{Discussion}

In this sample of hypertensive adults from North Carolina we found knowledge about some aspects of hypertension to be quite high. This finding highlights the success that has been achieved in high BP education over the last 30 years. North Carolinians seem generally aware that high BP can be life threatening, a finding that parallels the improvements in knowledge of the associations of hypertension with strokes and heart disease noted by the NHBPEP. ${ }^{1,2}$ They also are aware that Americans consume more sodium than they need. The vast majority $(86 \%)$ know that a BP recorded as over 140/90 $\mathrm{mm} \mathrm{Hg}$ is high.

Despite such successes with educating people about high BP (including the portrayal of hypertension as a "silent killer"14), our study suggests that a substantial number are still under the impression that people will be able to "feel" if their BP is high. Among patients already under treatment for hypertension, this notion may lead some to take their antihypertensive medication intermittently (eg, when they "feel bad"). Among patients who have not been diagnosed with hypertension, a lack of awareness that high BP generally does not cause 
Table 3. Bivariate Associations with Lower Hypertension Knowledge

\begin{tabular}{|c|c|c|}
\hline & n (\%) & $P$ \\
\hline \multicolumn{3}{|l|}{ Age category (years) } \\
\hline$<45$ & $16(21.6)$ & \multirow[t]{3}{*}{.03} \\
\hline $45-65$ & $47(18.1)$ & \\
\hline$>65$ & $52(28.6)$ & \\
\hline \multicolumn{3}{|l|}{ Sex } \\
\hline Male & $32(19.3)$ & \multirow[t]{2}{*}{.26} \\
\hline Female & $83(23.7)$ & \\
\hline \multicolumn{3}{|l|}{ Race } \\
\hline African-American & $49(29.2)$ & \multirow[t]{2}{*}{.009} \\
\hline White & $66(19.0)$ & \\
\hline \multicolumn{3}{|l|}{ Education } \\
\hline$<$ High school & $43(33.3)$ & \multirow[t]{3}{*}{$<.001$} \\
\hline High school graduate & $40(24.0)$ & \\
\hline Some college or more & $31(14.6)$ & \\
\hline \multicolumn{3}{|l|}{ BMI } \\
\hline$<25 \mathrm{~kg} / \mathrm{m} 2$ & $17(23.6)$ & \multirow[t]{3}{*}{.44} \\
\hline $25-30 \mathrm{~kg} / \mathrm{m} 2$ & $29(18.7)$ & \\
\hline$>30 \mathrm{~kg} / \mathrm{m} 2$ & $69(23.9)$ & \\
\hline \multicolumn{3}{|l|}{ Self-reported health } \\
\hline Excellent or very good & $19(17.3)$ & \multirow[t]{3}{*}{.084} \\
\hline Good & $41(20.2)$ & \\
\hline Fair or poor & $55(27.2)$ & \\
\hline \multicolumn{3}{|l|}{ Current smoker } \\
\hline Yes & $22(21.0)$ & \multirow[t]{2}{*}{.74} \\
\hline No & $92(22.4)$ & \\
\hline \multicolumn{3}{|l|}{ Known heart disease } \\
\hline Yes & $31(24.8)$ & \multirow[t]{2}{*}{.33} \\
\hline No & $72(20.6)$ & \\
\hline \multicolumn{3}{|l|}{ Known diabetes } \\
\hline Yes & $40(25.5)$ & \multirow[t]{2}{*}{.21} \\
\hline No & $66(20.4)$ & \\
\hline \multicolumn{3}{|c|}{ History of stroke or mini-stroke } \\
\hline Yes & $19(39.6)$ & \multirow[t]{2}{*}{.003} \\
\hline No & $86(20.8)$ & \\
\hline
\end{tabular}

symptoms may lead to some people not being screened. To increase the number of Americans who are aware of their hypertension, people need to appreciate that they must be screened to detect it. $^{15}$

Our data suggest 2 other misconceptions are also quite common. Almost 1 in 5 hypertensive patients believes taking medications will cure high $\mathrm{BP}$ (or is unsure about it). In addition, 1 out of 5 hypertensive patients believes there is nothing that can be done to prevent high $\mathrm{BP}$ (or is unsure about it). We noted that responses to these items were split fairly evenly between "Not sure" and "True." For the item, "There is nothing you can do to
Table 4. Independent Associations* with Lower Hypertension Knowledge $(n=455)$

\begin{tabular}{lll}
\hline & \multicolumn{1}{c}{$\begin{array}{c}\text { Odds Ratio } \\
(95 \% \text { CI })\end{array}$} & $P$ \\
\hline $\begin{array}{l}\text { Age category (years) } \\
\quad<45\end{array}$ & referent & \\
$45-65$ & $0.63(0.32-1.26)$ & .19 \\
$>65$ & $1.23(0.61-2.48)$ & .57 \\
Race/ethnicity & & \\
$\quad$ African-American & $1.77(1.10-2.86)$ & .019 \\
$\quad$ White & referent & \\
Education & & \\
$\quad<$ High school & $2.43(1.34-4.41)$ & .003 \\
$\quad$ High school graduate & $1.50(0.85-2.64)$ & .16 \\
$\quad$ Some college or more & referent & \\
Self-reported health & & \\
$\quad$ Excellent or very good & $0.79(0.41-1.54)$ & .49 \\
$\quad$ Good & $0.76(0.45-1.28)$ & .30 \\
$\quad$ Fair or poor & referent & \\
History of stroke or mini-stroke & $1.94(1.00-3.75)$ & .05 \\
\hline
\end{tabular}

*Adjusted for all other characteristics listed in the table.

prevent high blood pressure," $10.5 \%$ responded "True," and $11.6 \%$ responded "Not sure." For the item, "Taking medications will cure high blood pressure," 9.1\% responded "True," and 9.9\% responded "Not sure." These responses call for a greater effort to instruct patients that medications treat but do not cure hypertension. People also need to receive the message that lifestyle modifications (eg, weight control, aerobic exercise) can have an impact on whether they will develop hypertension. ${ }^{16}$

We found 3 characteristics to be associated with lower hypertension knowledge in general: AfricanAmerican race, having less than high school education, and a history of stroke/mini-stroke. The association with African-American race is particularly concerning because African-Americans tend to have earlier onset and hypertension that is more difficult to control. ${ }^{17}$ The association with less education is not surprising and is probably related to health literacy. ${ }^{18}$ As mentioned earlier, one of the recent studies of hypertension knowledge conducted in a national telephone survey found no overall differences by race or ethnicity. ${ }^{7}$ Our findings are probably different at least in part because of the items we chose to ask as well as the fact that our population was not restricted to those aged 50 years and older. In addition, there may indeed be regional differences, such that knowledge in the 
Southeast is lower than knowledge in other regions of the country.

Poorer control of hypertension and lower socioeconomic status (perhaps reflected in this study by less education) are 2 possible explanations for the increased stroke mortality in the Southeast (the "Stroke Belt"). ${ }^{19}$ Although it is not necessarily true that lower hypertension knowledge was causal in a chain of events leading to some patients' strokes, it seems reasonable that continuing to improve people's knowledge about hypertension could lead to improved recognition and control of high BP, which in turn could lead to decreased strokes.

Still, improving BP control in patients will probably require ongoing multifaceted efforts in addition to continuing to increased knowledge. For example, insufficient knowledge about treatment is but one barrier to medication adherence among people with hypertension. ${ }^{20}$ Other barriers include dosing schedules (eg, twice daily instead of once daily) and the cost of medications. ${ }^{20}$ Similarly, reducing BP in the population will require ongoing multifaceted efforts in addition to improving knowledge. For example, the majority of the population might understand that Americans consume too much sodium, but $80 \%$ of dietary sodium comes from processed and restaurant foods. ${ }^{21} \mathrm{Ef}-$ fectively reducing the population's sodium consumption will require policy development and implementation.

An important limitation of our study is the unknown validity of reducing the original 12 knowledge questions to the 6 questions we selected. As mentioned earlier, the primary objective of our questionnaire was not to assess knowledge. We chose items specific to various domains of hypertension knowledge to minimize response burden. It is also worth noting that we used Microsoft Word to assess the reading level of the questionnaire. This program may underestimate the readability of text. For convenience, we chose to pilot our questionnaire in a focus group of nurses, nursing assistants, and medical assistants. Although this group may not be representative of the intended study sample, we do not have any reason to suspect that the questions would have been interpreted differently.

A strength of this study was the high response rate. However, there are other notable considerations. Our sample did not include Hispanics, and is not necessarily representative of North Carolina, other states, or the United States in general. African-Americans, younger people, and men were less likely to respond to the survey. There may therefore be an association with sex that we did not detect, and the associations with age and race may be biased. If African-Americans who did not respond tended to have higher hypertension knowledge than those who did, our results will be biased away from the null. However, if African-Americans who did not respond tended to have lower knowledge than those who did, our results will be biased toward the null. There is also the consideration of selection bias in that people who volunteered to be in the cohort are more likely to be interested in health. One would assume that such people are actually more knowledgeable. If that is the case, our results may overestimate the hypertension knowledge of the target population. However, if volunteers have less knowledge than people who elected not to participate, our results will underestimate the hypertension knowledge of the target population. We surveyed people who knew they had high BP; knowledge may be different among people who either do not have high BP or have not yet been diagnosed with it.

This study highlights certain aspects of hypertension knowledge that need to be improved. Patients need to understand the difference between curing hypertension and treating it with medications. Clinicians should keep this in mind when educating their newly diagnosed hypertension patients. Two messages seem important to convey more broadly: (1) lifestyle modifications can prevent (or delay) hypertension, and (2) hypertension usually does not cause symptoms; to detect it, one must be screened. Specific public health strategies should continue to be developed to improve message delivery to African-Americans and people with less education. Community interventions, like those that have been conducted in settings such as churches, ${ }^{22}$ barber shops, ${ }^{23}$ and beauty shops, ${ }^{24}$ may be particularly well-suited to reaching people with educational messages about high BP. ${ }^{25,26}$

The authors would like to thank Carol Porter for assistance with some of the programming code used in this analysis and 3 anonymous reviewers for taking time out of their schedules to provide comments that helped strengthen this manuscript.

\section{References}

1. Moser M, Franklin SS. Hypertension management: results of a new national survey for the hypertension 
education foundation: Harris interactive. J Clin Hypertens (Greenwich) 2007;9:316-23.

2. Department of Health and Human Services, National Heart, Lung, and Blood Institute. National High Blood Pressure Education Program. Available at http://www.nhlbi.nih.gov/about/nhbpep/nhbp_ pd.htm. Accessed 1 October 2007.

3. Ong KL, Cheung BM, Man YB, Lau CP, Lam KS. Prevalence, awareness, treatment, and control of hypertension among United States adults 1999-2004. Hypertension 2007;49:69-75.

4. Fields LE, Burt VL, Cutler JA, Hughes J, Roccella EJ, Sorlie P. The burden of adult hypertension in the United States 1999 to 2000: a rising tide. Hypertension 2004;44:398-404.

5. Hyman DJ, Pavlik VN. Characteristics of patients with uncontrolled hypertension in the United States. N Engl J Med 2001;345:479-86.

6. Knight EL, Bohn RL, Wang PS, Glynn RJ, Mogun H, Avorn J. Predictors of uncontrolled hypertension in ambulatory patients. Hypertension 2001;38:80914.

7. Okonofua EC, Cutler NE, Lackland DT, Egan BM. Ethnic differences in older Americans: awareness, knowledge, and beliefs about hypertension. Am J Hypertens 2005;18:972-9.

8. Egan BM, Lackland DT, Cutler NE. Awareness, knowledge, and attitudes of older Americans about high blood pressure: Implications for health care policy, education, and research. Arch Intern Med 2003;163:681-7.

9. Oliveria SA, Chen RS, McCarthy BD, Davis CC, Hill MN. Hypertension knowledge, awareness, and attitudes in a hypertensive population. J Gen Intern Med 2005;20:219-25.

10. Sloane PD, Callahan L, Kahwati L, Mitchell CM. Development of a practice-based patient cohort for primary care research. Fam Med 2006;38:50-7.

11. Flesch R. A new readability yardstick. J Applied Psych 1948;32:221-33.

12. Martins D, Gor D, Teklehaimanot S, Norris K. High blood pressure knowledge in an urban AfricanAmerican community. Ethn Dis 2001;11:90-6.

13. Samal D, Greisenegger S, Auff E, Lang W, Lalouschek $W$. The relation between knowledge about hypertension and education in hospitalized patients with stroke in Vienna. Stroke 2007;38:1304.

14. Ashaye MO, Giles WH. For the patient. High blood pressure: the silent killer. Ethn Dis 2003;13:546-7.

15. Sheridan S, Pignone M, Donahue K. Screening for high blood pressure: a review of the evidence for the US Preventive Services Task Force. Am J Prev Med 2003;25:151-8.

16. Whelton PK, He J, Appel LJ, et al. Primary prevention of hypertension clinical and public health advisory from the National High Blood Pressure Education Program. JAMA 2002;288:1882-8.

17. Bosworth HB, Dudley T, Olsen MK, et al. Racial differences in blood pressure control: potential explanatory factors. Am J Med 2006;119:70.e9-15.

18. Williams MV, Baker DW, Parker RM, Nurss JR. Relationship of functional health literacy to patients' knowledge of their chronic disease: a study of patients with hypertension and diabetes. Arch Intern Med 1998;158:166-72.

19. Perry HM, Roccella EJ. Conference report on stroke mortality in the Southeastern United States. Hypertension 1998;31:1206-15.

20. Osterberg L, Blaschke T. Adherence to medication. N Engl J Med 2005;353:487-97.

21. Havas S, Dickinson BD, Wilson M. The urgent need to reduce sodium consumption. JAMA 2007;298: $1439-41$

22. Smith ED, Merritt SL, Patel MK. Church-based education: an outreach program for African-Americans with hypertension. Ethn Health 1997;2:243-53.

23. Hess PL, Reingold JS, Jones J, et al. Barbershops as hypertension detection, referral, and follow-up centers for black men. Hypertension 2007;49:1040-6.

24. Linnan LA, Ferguson YO. Beauty salons: a promising health promotion setting for reaching and promoting health among African-American women. Health Educ Behav 2007;34:517-30.

25. Kong BW. Community-based hypertension control programs that work. J Health Care Poor Underserved 1997;8:409-15

26. Fulwood R, Guyton-Krishnan J, Wallace M, Sommer E. Role of community programs in controlling blood pressure. Curr Hypertens Rep 2006;8:512-20. 